\title{
The Application of ANP Models in the Web-Based Course Development Quality Evaluation of Landscape Design Course
}

\author{
Xiaoyu Chen $^{1}$ and Lifang Qiao ${ }^{2}$ \\ College of Arts, Xi'an University of Architecture and Technology, Xi'an 710055, \\ China \\ School of Horticulture and Landscape Architecture, Henan Institute of Science \\ and Technology, Xinxiang 453003, China \\ 478708575@qq.com
}

\begin{abstract}
Web-based course is the important method in the landscape design teaching. In this paper, the ANP (Analytic Network Process) model has been adopted to evaluate the quality of the development of on-line courses, so as to provide the basis for preferred online courses. Conclude 10 evaluation indicators from 3 aspects of teaching, availability, and technology, and establish ANP model consisting of control layer, network layer, and alternatives. Four web-based courses of landscape design were chosen as the evaluation objects and the SD (Super Decisions) software was used to conduct the calculation. The result shows that: ANP is a practical science decision analysis method, comprehensively considering the mutually influential and feedback relationships of indicators, and is suitable for the evaluation and decision of the complex problems. The development quality evaluation of ANP which is applied in landscape design web-based courses is feasible, and the result of research can provide decision basis to web-based course development.
\end{abstract}

Keywords: Web-based course, ANP, Evaluation, Development quality, Landscape design

\section{Introduction}

In recent years, the information technology on the basis of the Internet has developed rapidly. Online education has been widely applied in recent years, which is a teaching mode that can implement informative education to students, using computer equipment and the Internet technology [1-3]. Compared with the traditional teaching mode, online teaching can better cultivate students' skills of the acquisition, process, analysis, innovation and utilization of information and their communication abilities. Online education takes information technology as a method to support lifelong learning and cooperative learning, which improves the efficiency of learning [4]. The important content of online education is to develop high-quality web-based courses [5]. The webbased course is the sum of demonstrating the teaching contents and implementing the teaching activities through the web. China attaches importance to the construction of webbased course in recent years. Projects such as "The Web-based course Construction Project of The New Century", "The National Excellent Course Sharing Project" were implemented to encourage the development of the web-based course by the Chinese Ministry of Education. The implementation of these projects effectively promotes the integration and sharing of online education resources and the training quality of talents.

China's rapid development of urban and rural construction leads to the fast development of the landscape design industry in recent years. With the increasing number of people who work as landscape designers, the market is asking more of the able designers. On the one hand, the landscape design major is a major that was established 
only a few years ago, thus the teaching quality needs strengthening. On the other hand, because many non-professional people also are engaged in landscape design, their business level also needs to be improved. Therefore, colleges and universities, vocational colleges and social people have a relatively large demand of the web-based courses of landscape design. Currently, domestic web-based course development is mainly led by academies and the web-based courses that are related to landscape design are about over 10. The web-based courses have enriched educational resources and learning channels, promoting the development of landscape design education. With the improvement of the requirements for learning, developing high-quality web-based courses become the main direction of the future development. Therefore, the study of the evaluation method of the development quality of web-based courses is very important.

Currently, the commonly used evaluation methods have two ways such as the qualitative evaluation and quantitative evaluation. The qualitative evaluation mainly adopts the experts or users scoring way according to the evaluation of the evaluation form. This method is easy to handle, but with a shortcoming of strong subjectivity; quantitative evaluation mainly uses methods such as AHP (Analytic Hierarchy Process) [6-7] and Fuzzy Evaluation [8], among which the AHP is widely applied in evaluation of web-based courses quality. AHP is an easy, flexible and practical multi-criteria decision method for quantitative analyzing of the qualitative problems. AHP divides various elements in complex problems into orderly layers that are mutually connected. However, this method only considers the domination which the high-layer elements exercise over the low-layer elements and meanwhile assumes that the elements of the same layer are independent with one another, ignoring the interaction and feedback between each factor. ANP has improved the inadequacy of AHP method, so it is more scientific and rational [9]. The key of ANP's solving problems is to use the method of comparing direct or indirect dominance degree to conduct a comprehensive analysis of interactional factors, which can obtain the blend weight so as to decide the optimal scheme. The ANP method is widely used in optimization selection of those schemes including industry development, optimization of supply chain, energy efficiency, business planning, investment planning and so on, which improves the efficiency and precision of optimization selection.

This research tries to apply ANP method to the quality assessment of which is applied in landscape design web-based courses, so as to provide a decision basis for the course development.

\section{Method and Model}

\subsection{Method}

Application procedure of ANP is as Follows:

(1) Choose evaluation indicators (Table 1). The primary selection has about 17 indicators. After consulting 28 professional teachers specialized in landscape from institutions of higher learning and vocational schools, students and 15 designers from landscape designing enterprises, 10 indicators among them are determined as the evaluation indicators.

(2) Establish ANP model. The model is divided into control layer, network layer and alternatives layer: the weight of every norm in control layer can all be obtained by AHP method; the network layer clusters the cluster and elements to form a network structure, and confirms the relationship between the cluster and elements; alternatives layer consists of 4 web-based courses of landscape design course. 
Table 1. The Evaluation Index System of the Web-based Courses of Landscape Design

\begin{tabular}{|c|c|c|}
\hline \multicolumn{2}{|c|}{ Control Layer } & Network layer \\
\hline \multirow{10}{*}{$\begin{array}{l}\text { Quality of web- } \\
\text { based course }\end{array}$} & \multirow{4}{*}{ Instructional } & Clear goals \\
\hline & & Complete systems \\
\hline & & Rich contents \\
\hline & & Reasonable organizations \\
\hline & \multirow{3}{*}{ Usability } & Sense of design \\
\hline & & User experience \\
\hline & & Legibility \\
\hline & \multirow{3}{*}{ Techniques } & Reliability \\
\hline & & Response speed \\
\hline & & Easy to maintenance \\
\hline
\end{tabular}

(3) Confirm the weight of norm in the control layer. The compared elements in ANP may not be independent but connected with each other. There are two methods to compare the dominance degree: direct dominance degree. Based on the principle given, compare the importance of the two elements to the principle; indirect degree of dominance. Based on the principle given, compare the influence of the two elements on the third element.

(4) Build a judge matrix; Using 1-9 scale to do comparison and check the consistency, which requires C. R. < 0.1 ; construct a weighted matrix.

(5) Calculate unweighted hypermatrix. unweighted hypermatrix's every column was sort vector, which was calculated by pairwise comparisons.

(6) Calculate weighted hypermatrix. Using each element of weighted matrix to multiply corresponding element pieces of unweight hypermatrix can obtain weighted hypermatrix. The sums of each row of elements in the weighted hypermatrix are all 1.

(7) Calculate limit hypermatrix. Weighted super matrix multiplies weighted super matrix until the convergence of the product, that is, each column gets final ordering vector after normalization. That means performing enough exponentiations in the hypermatrix till the data in each line go homogeneity, then the result of the significance ranking (weight) of each element will be obtained. In limitation hypermatrix, the value of each column represents the relative priority of the element towards the limitation of the relative element of the column according to each code.

(8) Cases optimization. The weight normalization of different cases. Choose the best case based on the ranking of the weighted value of different cases.

\subsection{Evaluation Model}

The model structure of ANP is relatively complex and the computation process is also relatively complex, which is hard to be applied to the practice without the assistance of the professional software. Super Decision software had successfully made ANP computing programmed, it can compute any ANP models and express the computing result completely. The computation adopted SD version 2.26 (Figure 1). 


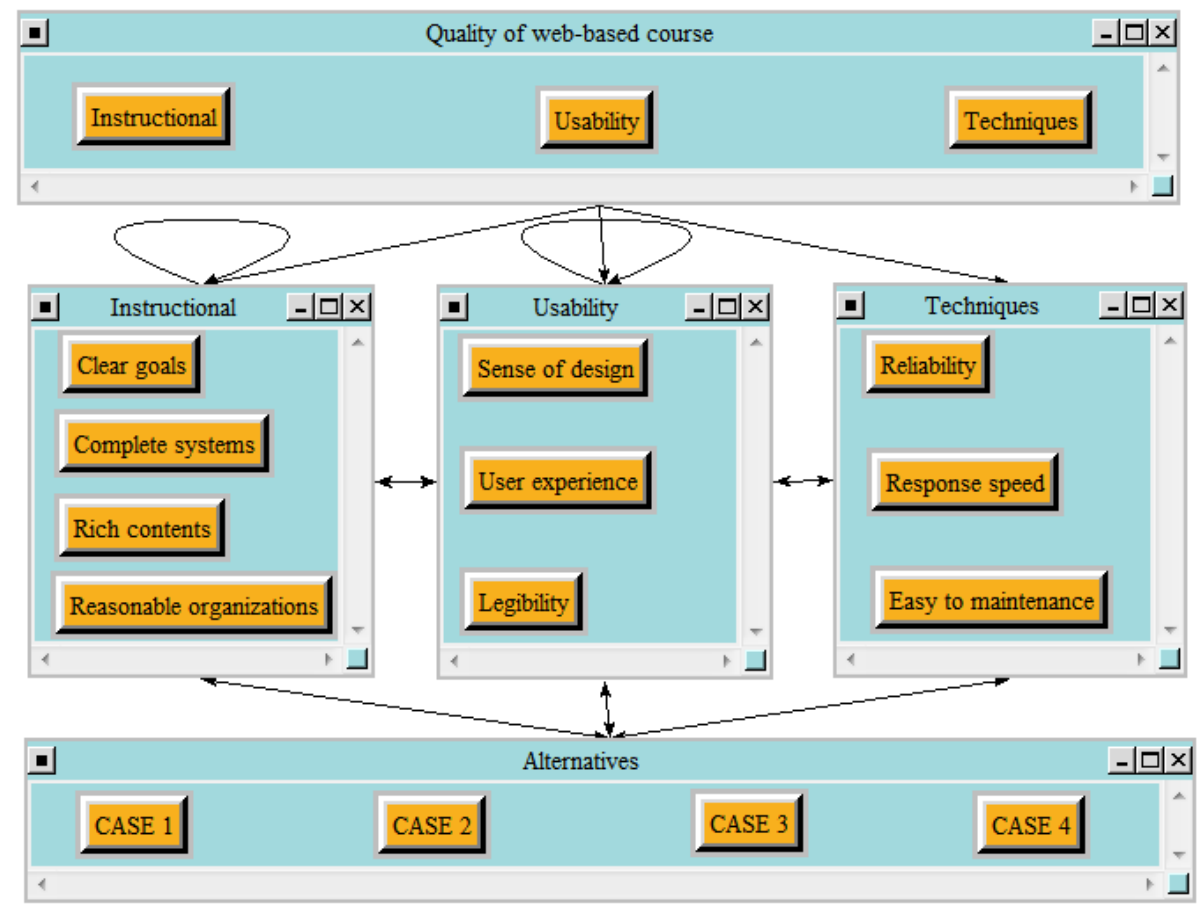

Figure 1. Model Structure in SD Software

\section{Result and Discussion}

\subsection{Case Selection}

According to the online search, the websites of four landscape design course are randomly selected to be evaluation cases (Table 2).

Table 2. The Websites of Web-based Courses of Landscape Design

\begin{tabular}{|l|l|}
\hline Case & \multicolumn{1}{|c|}{ Websites } \\
\hline Case1 & http://wlkc.gdqy.edu.cn/jpkc/solver/classView.do?classKey=9186503 \\
\hline Case2 & http://jpkc.shjgxy.net/jgsj/jxsp.htm \\
\hline Case3 & http://ylgh.7546m.com/ \\
\hline Case4 & http://ylgysj.qnzy.net/jxlx.asp \\
\hline
\end{tabular}

\subsection{Computing Process}

Unweighted hypermat3 has a relatively high development quality, while the development quality of case 4 is relatively low and that of case 1 and case 2 are in the middle (Figure 5). 


\subsection{Research Shortcomings}

\begin{tabular}{|c|c|c|c|c|c|c|c|c|c|}
\hline \multirow{2}{*}{\multicolumn{2}{|c|}{$\begin{array}{l}\text { Cluster } \\
\text { Node } \\
\text { Labels }\end{array}$}} & \multicolumn{4}{|c|}{ Alternatives } & \multicolumn{4}{|c|}{ Instructional } \\
\hline & & CASE 1 & CASE 2 & CASE 3 & CASE 4 & $\begin{array}{l}\text { Clear } \\
\text { goals }\end{array}$ & $\begin{array}{l}\text { Complete } \\
\text { systems }\end{array}$ & $\begin{array}{l}\text { Reasonable } \\
\text { organizations }\end{array}$ & Rich contents \\
\hline \multirow{4}{*}{$\begin{array}{l}\text { Alternat } \\
\text { ives }\end{array}$} & CASE 1 & 0.000000 & 0.000000 & 0.000000 & 0.000000 & 0.148967 & 0.149421 & 0.119272 & 0.116007 \\
\hline & CASE 2 & 0.000000 & 0.000000 & 0.000000 & 0.000000 & 0.339961 & 0.222909 & 0.232652 & 0.227763 \\
\hline & CASE 3 & 0.000000 & 0.000000 & 0.000000 & 0.000000 & 0.428288 & 0.513581 & 0.568909 & 0.570537 \\
\hline & CASE 4 & 0.000000 & 0.000000 & 0.000000 & 0.000000 & 0.082785 & 0.114089 & 0.079166 & 0.085693 \\
\hline \multirow{4}{*}{$\begin{array}{l}\text { Instruct } \\
\text { ional }\end{array}$} & $\begin{array}{l}\text { Clear } \\
\text { goals }\end{array}$ & 0.268348 & 0.134895 & 0.106450 & 0.433796 & 0.000000 & 0.000000 & 0.000000 & 0.000000 \\
\hline & $\begin{array}{l}\text { Complete } \\
\text { systems }\end{array}$ & 0.166097 & 0.112076 & 0.413117 & 0.271085 & 0.000000 & 0.000000 & 0.000000 & 0.000000 \\
\hline & $\begin{array}{l}\text { Reasonable } \\
\text { organizations }\end{array}$ & 0.112897 & 0.248266 & 0.120108 & 0.142226 & 0.000000 & 0.000000 & 0.000000 & 0.000000 \\
\hline & Rich contents & 0.452658 & 0.504763 & 0.360325 & 0.152893 & 0.000000 & 0.000000 & 0.000000 & 1.000000 \\
\hline
\end{tabular}

Figure 2. Unweighted Hypermatrix in SD Software (Partial)

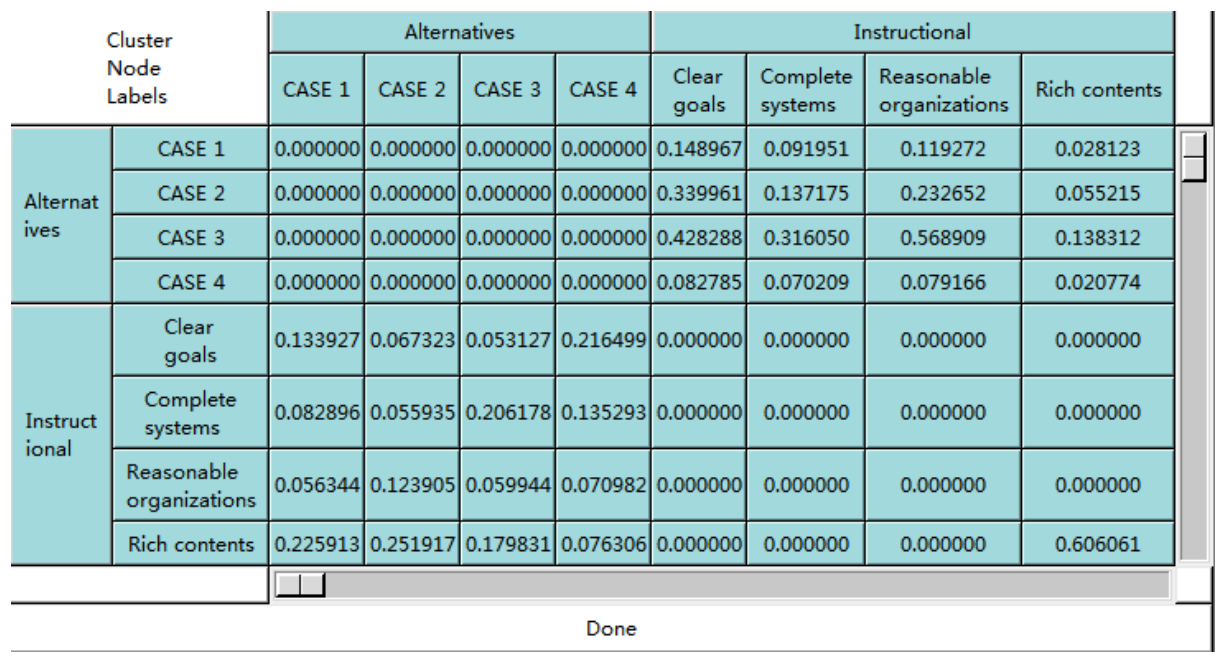

Figure 3. Weighted Hypermatrix in SD Software (Partial)

\begin{tabular}{|c|c|c|c|c|c|c|c|c|c|}
\hline \multirow{2}{*}{\multicolumn{2}{|c|}{$\begin{array}{l}\text { Cluster } \\
\text { Node } \\
\text { Labels }\end{array}$}} & \multicolumn{4}{|c|}{ Alternatives } & \multicolumn{4}{|c|}{ Instructional } \\
\hline & & CASE 1 & CASE 2 & CASE 3 & CASE 4 & $\begin{array}{l}\text { Clear } \\
\text { goals }\end{array}$ & $\begin{array}{l}\text { Complete } \\
\text { systems }\end{array}$ & $\begin{array}{l}\text { Reasonable } \\
\text { organizations }\end{array}$ & Rich contents \\
\hline \multirow{4}{*}{$\begin{array}{l}\text { Alternat } \\
\text { ives }\end{array}$} & CASE 1 & 0.066809 & 0.066809 & 0.066809 & 0.066809 & 0.066809 & 0.066809 & 0.066809 & 0.066809 \\
\hline & CASE 2 & 0.081533 & 0.081533 & 0.081533 & 0.081533 & 0.081533 & 0.081533 & 0.081533 & 0.081533 \\
\hline & CASE 3 & 0.146357 & 0.146357 & 0.146357 & 0.146357 & 0.146357 & 0.146357 & 0.146357 & 0.146357 \\
\hline & CASE 4 & 0.043723 & 0.043723 & 0.043723 & 0.043723 & 0.043723 & 0.043723 & 0.043723 & 0.043723 \\
\hline \multirow{4}{*}{$\begin{array}{l}\text { Instruct } \\
\text { ional }\end{array}$} & $\begin{array}{l}\text { Clear } \\
\text { goals }\end{array}$ & 0.033331 & 0.033331 & 0.033331 & 0.033331 & 0.033331 & 0.033331 & 0.033331 & 0.033331 \\
\hline & $\begin{array}{l}\text { Complete } \\
\text { systems }\end{array}$ & 0.051641 & 0.051641 & 0.051641 & 0.051641 & 0.051641 & 0.051641 & 0.051641 & 0.051641 \\
\hline & $\begin{array}{l}\begin{array}{l}\text { Reasonable } \\
\text { organizations }\end{array} \\
\end{array}$ & 0.028362 & 0.028362 & 0.028362 & 0.028362 & 0.028362 & 0.028362 & 0.028362 & 0.028362 \\
\hline & Rich contents & 0.194593 & 0.194593 & 0.194593 & 0.194593 & 0.194593 & 0.194593 & 0.194593 & 0.194593 \\
\hline & & \multicolumn{8}{|l|}{$\square$} \\
\hline \multicolumn{10}{|c|}{ Done } \\
\hline
\end{tabular}

Figure 4. Limit Hypermatrix in SD Software (Partial) 


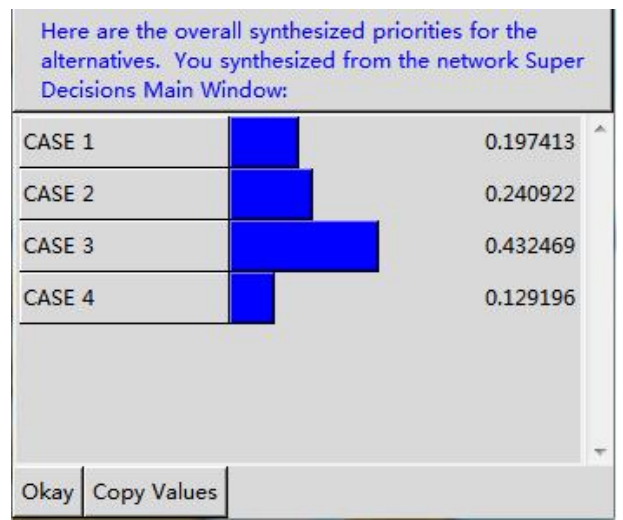

Figure 5. Result of Web-based Course Optimization in SD Software

There are many indexes influencing the quality of web-based courses, and there are different features of different majors and lessons. It is very critical to select the proper evaluating indicator according to the characteristics of the specialized courses, because the representativeness of the evaluating indicator will directly affect the accuracy of evaluation. Although we have sought advice from teachers and students of related disciplines as well as employees of landscape design enterprises for the selected indexes in this study, they still need to be further improved. Besides, since SD software is unable to operate group decision-making, and the judgment is done by discussions by experts in this research, hence, there are certain errors in the result.

\section{Conclusion}

The web-based course of landscape design plays an important role in promoting the teaching quality of modern long-distance education. Studying the evaluation method of Quality of web-based course helps promote the course development. ANP is a kind of decision-making method suitable for non-independent hierarchical structure. The development of ANP which is applied in landscape design web-based courses can reflect the interrelationship between each elements or adjacent layers, and also improve the accuracy of evaluation. The software program SD is a professional software program to solve the problem of ANP, and it can achieve the fast solution of ANP model and provide convenience for the application of ANP model. ANP model still belongs to the evaluation mode that is both qualitative and quantitative and is affected by human subjective factors. Further research is still needed on how to improve the rationality of the evaluation results.

\section{References}

[1] J. Delahunty, P. Jones and I. Verenikina, "Movers and shapers: Teaching in online environments", Linguistics and Education, vol. 28, (2014), pp. 54-78.

[2] Z. Ibrahim and A. A. Aziz, "Instructional design theory on teaching delivery and evaluation online for graphic design courses", Procedia - Social and Behavioral Sciences, vol. 67, (2012), pp. 606-615.

[3] C. J. Bailey and K. A. Card, "Effective pedagogical practices for online teaching: Perception of experienced instructors", The Internet and Higher Education, vol. 12, no.3-4, (2009), pp. 152-155.

[4] V. Cana, "An investigation on evaluation of students' achievement in on-line teaching", Procedia Social and Behavioral Sciences, vol. 9, (2010), pp. 1550-1555.

[5] B. Perry, "Using photographic images as an interactive online teaching strategy", The Internet and Higher Education, vol. 9, no. 3, (2006), pp. 229-240.

[6] H. F. Lin, "An application of fuzzy AHP for evaluating course website quality", Computers \& Education, vol. 54, no. 4, (2010), pp. 877-888.

[7] A. Certa, M. Enea and F. Hopps, "A multi-criteria approach for the group assessment of an academic course: A case study', Studies in Educational Evaluation, vol. 44, (2015), pp. 16-22.

[8] K. Kamvysi, K. Gotzamani, A. Andronikidis and A. C. Georgiou, "Capturing and prioritizing students' requirements for course design by embedding Fuzzy-AHP and linear programming in QFD", European Journal of Operational Research, vol. 237, no. 3, (2014), pp. 1083-1094. 
[9] J. K. Chen and I. S. Chen, "Using a novel conjunctive MCDM approach based on DEMATEL, fuzzy ANP, and TOPSIS as an innovation support system for Taiwanese higher education”, Expert Systems with Applications, vol. 37, no. 3, (2010), pp. 1981-1990.

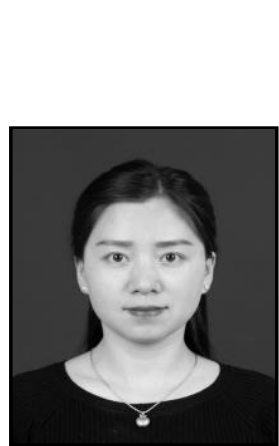

\begin{abstract}
Authors
Xiaoyu Chen, female, she received a bachelor degree from Xi'an University of Architecture and Technology in 2002, and she received a master degree from Xi'an University of Architecture and Technology in 2005, now she is a lecture in the College of Arts, Xi'an University of Architecture and Technology. Her current research interests include the sustainable architecture, the landscape planning and design.
\end{abstract}

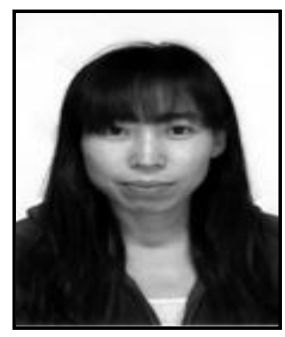

Lifang Qiao, female, she received a master degree from Central South University of Forestry and Technology, Changsha, China, in 2004, now she is an associate professor in the School of Horticulture and Landscape Architecture of Henan Institute of Science and Technology, Xinxiang, China. Her current research interests include the landscape evaluation and the application of mathematical models in landscape optimization. E-mail: qiaolifang2014@gmail.com. 
International Journal of Multimedia and Ubiquitous Engineering Vol.10, No.9 (2015) 